\title{
Akademik/Kampüs Romana Karşılaştırmalı Bir Yaklaşım: Eating People is Wrong \& Bir Bilim Adamının Romanı
}

\section{A Comparative Study to Academic/Campus Novel: Eating People is Wrong \& Bir Bilim Adamının Romanı}

Geliş / Received: 01/10/2021

Yusuf Ziyaettin TURAN ${ }^{1 *}$

Revize / Revised:03/11/2021

Kabul / Accepted: 15/11/2021

\section{ÖZ}

Türk Edebiyatında pek bilinmemekle birlikte Batı Edebiyatlarında ve özellikle İngiliz Edebiyatında konusunu üniversite akademik yaşamına adayan roman türüne akademik/kampüs roman türü denilmektedir. Bu tür romanlarda genellikle başkişiler o üniversitede çalışan akademik personel olmaktadır. Bu akademik personel de genellikle İngilizce bölümünde çalışan profesörlerdir. Akademik/kampüs romanlarının ortaya çıkma sebebi dönemin üniversitelerindeki akademik düzeni ve kadroları eleştirmektir. Bu sebeple bu tür romanlarda genellikle ironik ve hicivli bir dil kullanılmaktadır. Ayrıca akademik/kampüs romanlarında yer alan karakterler genellikle kendi kişilikleriyle, içinde bulundukları dönem, toplumla ve çalışma arkadaşlarıyla sorunları olan akademisyenlerdir. Bu çalışmada, birisi İngiliz Edebiyatı'ndan Malcolm Bradbury'nin Eating People is Wrong ve diğeri Türk Edebiyatından Oğuz Atay'ın Bir Bilim Adamının Romanı adlı eserleri akademik/kampüs roman türü bağlamında mukayeseli bir yöntemle incelenmekte ve tespit edilen bulgular yine mukayeseli olarak değerlendirilmektedir. Yapılan bu mukayeseli inceleme sonucu, kurgulanma formatları farklı olsa da her iki romanın akademik/kampüs roman özelliklerine sahip olduğu ve böylece bu türde örnek gösterilebilecek eserler oldukları tespit edilmiştir.

Anahtar Kelimeler-Akademik/Kampüs roman, Eating People is Wrong, Bir Bilim Adamının Romanı, Malcolm Bradbury, Ŏguz Atay

\begin{abstract}
In Western literature, particularly in English literature, the kind of novel that deals with university academic life is named as academic/campus novel though it has not been known much in Turkish literature. In this kind of novels, the main character is usually an academic person who works in university. Besides, this academic person is usually a professor at English department. The main stream at the back of this kind of novels is to criticize the academic order and academic people in that period. Therefore, the language of these novels is usually ironic and satirical. Furthermore, the academic people in these novels usually have problems with themselves, the period, the society, and the colleagues. In this paper, Malcom Bradbury's Eating People is Wrong from English literature and Oğuz Atay's Bir Bilim Adamının Romanı from Turkish literature are comparatively studied in the context of academic/campus novel genre, and the findings are evaluated with a comparative method. After this comparative study, it has been identified that both novels have the academic/campus novel traits and can be given as examples of this genre.
\end{abstract}

Keywords- Academic/Campus roman, Eating People is Wrong, Bir Bilim Adamının Romant, Malcolm Bradbury, Ŏğ Atay

\footnotetext{
1 *Sorumlu Yazar, Dr. Öğr. Üyesi, Uşak Üniversitesi, Fen-Edebiyat Fakültesi, Batı Dilleri ve Edebiyatı Bölümü, yusufz.turan@usak.edu.tr, (https://orcid.org/0000-0001-9551-3594)
} 


\section{GİRIŞ̧}

Roman tanımı gereği, belirli bir uzunluğa sahip düz yazı olarak tanımlanmakla beraber resmi olarak ilk tarih sahnesine çıktığ 1 18. Yüzyıldan itibaren içeriğine bağlı olarak pikaresk roman, mektup roman, tarihi roman, gotik roman, bilim kurgu, sosyal roman, modernist roman vb. gibi birçok çeşide ayrılmaktadır. Bununla birlikte, özellikle postmodern dönemle birlikte bu temel roman türlerine üstkurmaca, tarih yazımsal postmodern roman, satirik roman, bildungsroman, sömürge sonrası roman vb. gibi yeni alt roman türleri sürekli olarak eklenmektedir (Hawthorn, 1997: 53-65; Abrams, 1999: 190-196; Baldick, 2001: 173-174). Bu son dönem roman akımları içinde 'Akademik Roman' olarak da bilinen 'Kampüs Roman', özellikle İngiltere'de 1944 Eğitim Reformu (Education Act of 1944) sonrasında hızla ortaya çıkan Kırmızı Tuğla Üniversiteleri (Redbrick Universities) sayesinde günümüzde popüler bir roman türü olarak karşımıza çıkmaktadır (Womack, 2002: 28). İngiliz romancılar arasında özellikle akademik/kampüs roman türünde ünlenen yazarlar Kinsley Amis, David Lodge, Howard Jacobson, Andrew Davies ve bu çalışmada eseri inceleme konusu olan Malcolm Bradbury’dir (Shaffer, 2006: 36). Belirtildiği üzere, İngiliz menşeili olarak tescil edilen akademik/kampüs roman türüne Türk Edebiyatı'ndan örnek vermek kolay değildir. Çünkü bu türde değerlendirilebilecek Türkçe eser sayısı hemen hemen yoktur. Öyle ki, 'kampüs roman' terimi akademik veri tabanlarında tarandı̆̆ında sadece Aytaç Ören'in 'Kampüs Roman Ve David Lodge'un Kampüs Romanları' adlı çalışması bulunuyor. Bu sebeple, bu çalışmada ele alınan Türk Edebiyatından Oğuz Atay'ın aynı zamanda üniversite hocası olan Prof. Mustafa İnan'ın yaşam öyküsünü anlatan Bir Bilim Adamının Romanı adlı eserinin kampüs roman kategorisinde, İngiliz Edebiyatından Eating People is Wrong romanı ile karşılaştırmalı olarak değerlendirilmesi, bu türün hem Türk Edebiyatında daha fazla tanınmasına hem de bu alanda ileride yapılacak çalışmalara şüphesiz katkı sağlayacaktır. Bu çalışmada, buna bağlı olarak, öncelikle İngiliz Edebiyatından Malcolm Bradbury'nin Eating People is Wrong (1959), ve daha sonra Türk Edebiyatından Oğuz Atay'ın Bir Bilim Adamının Romanı (1975) akademik/kampüs romanı bağlamında ele alınacak ve çalışmanın sonuç bölümünde her iki eserin akademik/kampüs roman özellikleri benzerlikleri ve farklılıkları karşılaştırmalı edebiyat yöntem bilimi doğrultusunda değerlendirilecektir.

\section{AKADEMIK/KAMPÜS ROMAN}

Kampüs ya da akademik roman 20. Yüzyılın ikinci yarısında Avrupa'da ve özellikle İngiltere'de yıldızı parlayan bir edebi türdür. Bu romanların mekânı genellikle İngiltere'de kırmızı-tuğla üniversiteleri olarak tanımlanan, ama kesin olarak ismi bilinmeyen bir taşra üniversitesidir. Baş karakter genellikle bir İngilizce profesörü olup, diğer karakterler üniversite öğrencileri ve personelidir. David Lodge’un, Kingsley Amis'in Lucky Jim romanının giriş bölümünde belirttiği üzere, akademik/kampüs roman türü ilk olarak Amerikalı bilinmekle birlikte, daha sonra İngiltere'de üne kavuşmuştur: “Lucky Jim şimdiye kadar özellikle bir Amerikan olayı olarak bilinen roman türünün kesinlikle İngiliz versiyonudur. Benim kendi üniversite hayatıyla ilgili romanlarım, sonra Malcolm Bradbury, Howard Jacobson, Andrew Davies ve diğerlerininkiler büyük ölçüde ona borçludurlar" (Lodge, 2000: Vİ̇-Vİï). Bu yüzden, Kingsley Amis'in Lucky Jim (1954) isimli romanı İngiltere'de ilk akademik/kampüs roman örneği olmakla birlikte Malcolm Bradbury'nin Eating People is Wrong (1959) ve David Lodge'un Changing Places: A Tale of Two Campuses (1975), Small World: An Academic Romance (1984) ve Nice Work (1988) üçlemesi onu takip etmiştir. Böylece hem Amis'in hem de Bradbury'nin romanları akademik romanın ilk örneklerini teşkil etmektedir. Bu romanların mekânı ve dönemi II. Dünya Savaşı hemen sonrasındaki İngiltere'dir. Bu sebeple, bu dönem yazılan akademik/kampüs romanlarının atmosferi donuk ve karamsar olup, kahramanları da tıpkı toplumun o dönemki hali gibi yersiz ve dışlanmış haldedirler. Malcolm Bradbury toplumun bu durumunu şu şekilde ifade etmektedir: “1945'te savaş bittiğinde, birçok Avrupa şehri bombardımanlar sonucu tahrip olmuş ya da yaşanılamaz hale dönmüş, kıtanın büyük bölümü harabeye dönmüş, endüstriyel faaliyetler durmuş, hasatlar olgunlaşmamış, bütün sınırlar değişmiş ve pek çok Avrupalı yersiz yurtsuz kalmış haldedir" (Bradbury, 1994: 265). Belirtildiği üzere, bu tür eserler II. Dünya Savaşı sonrası İngiltere toplumunun genelde sosyal ve özelde akademik yaşamına ayna tutmaktadırlar ve dolasıyla akademik/kampüs romanlarının kahramanları, dönemin Avrupası'nın toplum ruhunu özel ve iş hayatlarında aynen yaşamaktadırlar.

Tarihsel olarak kampüs romanın 1950 sonrasında yıldızının parlaması, İngiltere'de ortaya konan Refah Devlet (Welfare State) düzeni ve 1944'teki Eğitim Hareketi (Education Act of 1944)'ne bağlıdır. Bu düzenlemeler sayesinde birçok alt ve işçi sınıf kökenli öğrenci Oxford ve Cambridge gibi köklü üniversitelerde hükümet bursuyla okuma firsatı buldu. Ne var ki, bu alt ve işçi sınıftan gelme öğrenciler daha önce sadece üst sınıftan öğrencilerden oluşan bu gittikleri üniversitelerde kendilerini, yukarıda bahsedilen toplumun genel haline de paralel olarak, yabancı ve dışlanmış hissettiler. Aynı durum, öğrenim hayatlarını tamamladıktan sonra kendilerine iş ve kariyer kapısı olan Kırmızı Tuğla (Redbrick University) olarak nitelenen taşra üniversitelerinde de başlarına gelmiştir. Böylece, "birçok önemli kampüs roman bu dişlanmış kişilerin hayatta kalma ve birçok zorlukla başa 
çıkma mücadelesine 1şık tutmaktadır” (Connor, 2001: 70). Benzer şekilde, Sanders kampüs romandan “1970’lerin kampüs romanı dönemin hızla ilerleyen yükseköğrenim dünyasının akademik hırslarını ve gerilimlerini yansıtma görevi üstlendi” (Sanders, 1994: 378) şeklinde bahseder. Örneğin, Amis'in Lucky Jim'inde Jim Dixon karakterinde olduğu gibi, kahramanlar üstlerinin onlara davranışları sebebiyle aşağılık kompleksine kapılmakta ve akademik gelecekleri hususunda kaygıya düşmektedirler.

Böylece kuramsal olarak akademik/kampüs romanının fonksiyonunun, dönemin üniversitelerindeki çarpıklıkları, alt üst ilişkilerinden ortaya çıkan akademik güçlükleri ve aynı zamanda bu kaotik ortamda alt ve işçi sınıf kökenli akademisyenlerin kendilerine yer edinme ve hayatta kalma çabalarını, eleştirel bir yaklaşımla ortaya koymak olduğu anlaşılmaktadır. Bu işlevi icra ederken genellikle hicivli bir dil kullanmaktadırlar. Böylece, akademik/kampüs roman, komik roman türünde olduğu gibi bir taraftan komik-güldürü unsurlarına sahip olurken, diğer taraftan eleştirel bir tutumla akademik dünyayı ve kişileri hicvetmektedir. Buna bağlı olarak, çalışmanın bu noktasından sonra, başkişileri üniversitede profesör olarak çalışan iki akademisyenin çelişkilerle ve güçlüklerle dolu hayatını konu edinen Malcolm Bradbury'nin Eating People is Wrong ve Oğuz Atay'ın Bir Bilim Adamının Romanı adlı eserleri akademik/kampüs roman geleneği bağlamında değerlendirilecektir. Yazım yılına göre sırasıyla önce Malcolm Bradbury’nin ve daha sonra Oğuz Atay'ın romanı ele alınacaktır.

\section{AKADEMIK/KAMPÜS ROMAN OLARAK EATING PEOPLE IS WRONG}

Eleştirmen ve romancı Malcolm Bradbury’nin kaleme aldığı Eating People is Wrong (1959), yukarıda belirtildiği üzere kampüs roman olmasının yanı sıra yazarının ilk romanı olma özelliğine de sahiptir. Romanın akademik olma özelliğinin yanında otobiyografik olma durumu da vardır. Çünkü Bradbury bu romanının konusunu 1950’de öğrenci olarak gittiği Leicester Üniversitesi'nden esinlenmiştir. Romanın kahramanı Stuart Treece'i de kendisinin yirmili yaşlardaki hali olarak nitelendirmektedir (Bradbury, 2021). Bunlara ek olarak, yine David Lodge'un yukarıdaki sözlerine istinaden, Bradbury bu romanı yazarken ilk kampüs roman yazarı olan Kingsley Amis ve onun eseri Lucky Jim (1954)'den çok etkilenmiştir. Dolasılyla Eating People is Wrong'un geçtiği mekân İngiltere'de Kırmızı Tuğla Üniversitesi (Redbrick University) olarak nitelenen bir taşra üniversitesi olup dönem de savaş sonrası 1950'li yıllardır. Romanın kahramanı, Stuart Treece kampüs romanlarına uygun olarak İngilizce bölümünde bir profesördür. Treece kırklı yaşlarında bekâr bir akademisyendir. Ne var ki, Treece dönemin sosyal ve toplumsal havasına uygun olarak genel olarak hayata ve özel olarak akademik kariyerine karşı karamsar ve isteksiz bir bakış açısına sahiptir. Roman şu cümlelerle başlar:

“Dönem yeni başlamıştı. İngilizce bölüm başkanı Profesör Treece buz gibi parıldayan soğuk Ekim güneşine karşın sırtını pencereye vererek, omuzlarının üzerinden oraya buraya saçılmış kâğıt yığııı arasından solgun yüzlü genç öğrencilerine doğru masasına yerleşmişti” (Bradbury, 1962: 9).

Görüldüğü üzere, daha başlangıç cümlesinden itibaren romanın genel havası okura hissettirilmektedir; hava soğuk olduğu gibi karakterler de solgun ve cansızdırlar. Karakterlerin bu ruh hali romanın ikinci sayfasında Treece üzerinden şu şekilde açıklanır:

“İnsanlar sinirli fakat ortalıkta sinirlenecek bir şey de gözükmüyor; belki de insanlar bu yüzden sinirli. Belki de onu bu hale sokan güdü, dünyanın sürekli ilerlediği düşüncesiyle kendisini özdeşleştirme hissiyatının çökmesi. Taşrada yaşamak bu hissiyatı kuvvetlendiriyor. Yeni dönem ve yeni öğrenciler onu ne canını sıkar ne de heyecanlandırır; mevsimlerin değiştiğini bile güçlükle fark eder. Her şey rutine bağlanmış durumdadır; ne kadar umması ve çok fazlasını istememesi gerektiğini bilecek uzunlukta üniversitede bulunmaktadır” (Bradbury, 1962: 10).

Yukarıdaki alıntı, dönemin, yani 1950'lilerin özellikle üniversite mezunu genç aydınlarının topluma bakış açısını vermesi açısından dikkat çekicidir. Dönemin gençleri, buna romanın kahramanı Profesör Treece de dâhil, hayattan ve toplumdan umduklarını bulamamışlardır. O yüzden kendilerini ‘Kızgın Gençler’ (Angry Young Men) olarak nitelemektedirler. 'Kızgın Gençler' hareketinin başını tiyatroda 'Look Back in Anger' (1956) isimli ünlü oyunuyla John Osborne, romanda ise John Braine ve Alan Sillitoe çekmektedir (Head, 2002: 50). Diğer taraftan Bradbury'nin 'Kızgın Gençler' hareketine gönderme yapmasının asıl sebebi Treece'in karakterini daha iyi ortaya koyabilmektedir. Treece'de Kızgın Gençler gibi içinde bulunduğu dönemden, toplumdan ve çalışma ortamı olan üniversite hayatından beklentilerini bulamamış, kızmakta ama neye kızdığını kendisi de bilmemektedir. Malcolm Bradbury Treece'i karakter olarak tanımlarken, isminin de çağrışım yaptığı üzere, kendisini hala 1930'luların edep ve iyi niyetini kendisine şiar edinmiş ancak bunları yaşadığı hayatta ve çevresinde bulamadığı için boşlukta kalmış ve son bir umut kapısı olarak liberalizme sarılan birisi olarak ifade etmektedir: 
"Benim sorunum şu ki diye düşündü Treece, ben doğuştan günaha inanan liberal hümanist birisiyim. Ben insanı, gücünü sadece kendisini daha medeni ve iyi olma yolunda çaba harcayan asil bir varlık olarak kabul ediyorum; ancak onun bütün çabası her şey göz önüne alındığında temelde fenadır ve ilerledikçe bu durum da büyümeye devam edecektir" (Bradbury, 1962: 12).

$\mathrm{Bu}$ ifadelerinden de anlaşılacağ dünya arasında arada kalmış bir karakterdir. Bu arada kalmışlık onun için sadece beklenti noktasında sınırlı değildir. Bu çıkmaz onun kişilik yapısına ve belirtildiği üzere akademik yaşamına da yansımaktadır. Akademik kariyer ve çalışma ortamı olan üniversiteden artık herhangi bir beklentisi kalmamıştır. Benzer şekilde, kırk yaşında olmasına rağmen yaşamında evlilik ve mutluluk gibi kavramlara da yer yoktur. Öyle ki, sevdiğini zannettiği ve partilere birlikte gittiği Emma isimli yüksek lisans öğrencisi, onu sevmek ve kendisine layık bir koca olarak görmekten ziyade ona acımaktadır: "Zavallı, zavallı Treece diye düşündü Emma; ne de olsa o halden anlayan birisiydi" (Bradbury, 1962: 37). Profesör Treece'in hayatındaki bu olumsuzluklar, belirtildiği üzere dönemin karamsar havasıyla uyuşmaktadır.

Profesör Treece'i akademik/kampüs roman kahramanı yapan bir başka özelliği de onun, daha önceki akademik yapıdan farklı olarak, alt-işçi sınıf kökenli bir akademisyen olmasıdır. Belirtildiği üzere, Refah Devlet ve 1944 Eğitim Hareketi öncesi üniversitelerde akademik kadrolar üst sınıftan kişilerden oluşmaktaydı ve müstakbel akademisyenlerin de bu tip aile ve sosyal çevreden gelmeleri bekleniyordu. Ne var ki, devletin daha adil bir düzen için getirdiği bu yaklaşımlar sonucu, Treece gibi II. Dünya Savaşı sırasında kendisi itfaiyecilik yapmış ve babası duvar kâğıdı satıcısı olan birisi üniversitede profesör olmuştur:

“Aslında babasının bir duvar kâğıdı satan dükkanı vardı ve bir keresinde babasına insanların ilişkilerini sadece alıcılar ve satıcılar olarak nitelemenin yanlış olduğunu söylediğinde, babası ona boş boş bakarak, 'Başka türlü nasıl olacak?' diye sormuştu. Treece böyle bir aileden geldiği için hiçbir zaman utanmamıştı, ancak babasının bu karşılığına şaşırmıştı" (Bradbury, 1962: 47).

Eating People is Wrong romanında, ana karakter İngilizce Profesörü Stuart Treece'nin kişiliği ve hayat felsefesinin yukarıdaki değerlendirilmesinden sonra, burada romanın diğer bir akademik/kampüs romanı özelliği olan üniversite ortamı ve orada eğitim gören öğrenci profilleri kısaca ele alınacaktır. Daha önce de belirtildiği üzere, Eating People is Wrong bir taşra kasabasındaki üniversite ortamını konu edinmektedir. Bu dönem İngiliz taşra üniversitelerinde eğitim ortamı vasatın altında kalmaktadır ve buraya gelen öğrenciler, dahi de olsalar, yeterli donanımı ve vizyonu vermekten uzaktırlar. Benzer şekilde bu üniversiteye gelen ögrenci karakter tipleri de pek iç açıcı değildir:

"Her yıl öğrenciler, bir üç yıl daha üniversite yemekhanesinden faydalanmak için, spor kulüplerine katılmak, her cumartesi akşamı düzenlenen öğrenci birliği partilerinde bulunmak, haftalık vals ve tango danslarında boy göstermek, barlarda bira içmek, ıslak banklarda öpebilecekleri kızları ayartmak, yardım toplama günlerinde polise domates atmak, üç yıl boyunca bulabildikleri kadar fazla kızla çıkmak ve son olarak da düşük bir diploma derecesi alarak ve üniversite eğitiminden yeterince nasiplenmeden öğretmenliğe ya da ticarete adım atmak için buraya gelirler" (Bradbury, 1962: 11-12).

$\mathrm{Bu}$ alıntıdan açıkça anlaşıldığı üzere, dönemin İngiltere'sinde Kırmızı Tuğla Üniversitesi (Redbrick University) olarak tanımlanan eğitim kurumlarında akademik yaşam hem orada ders veren hocalar hem de orada eğitim alan üniversite öğrencileri için pek parlak değildir. Dönemin üniversiteleri fiziksel olarak vardır ancak içerik ve işlev olarak yeterli değildirler. Üstelik o dönem, iyi eğitim almamış öğrencileri mezun ederek, bu üniversitelerin kendi mevcudiyetlerinin sebebi ve gereği olan topluma faydalı ve nitelikli bireyler yetiştirme idealinden gün geçtikçe uzaklaşmış oldukları anlaşılmaktadır. Dolayısıyla Bradbury'nin Eating People is Wrong romanı dönemin üniversite eğitim kadrosuna, öğrencilerine ve eğitim faaliyetlerine olumsuz eleştirel bir bakış açısıyla yaklaşmaktadır. Çalışmanın bundan sonraki bölümünde, Türk Edebiyatından Oğuz Atay’ın Bir Bilim Adamının Romanı isimli çalışması akademik/kampüs roman türünde değerlendirilmesi yapılacaktır.

\section{AKADEMIK/KAMPÜS ROMAN OLARAK BIR BILIM ADAMININ ROMANI}

Bir Bilim Adamının Romanı Oğuz Atay'ın 1975'te üniversiteden hocası olan Profesör Mustafa İnan'ın hayatını kaleme aldığı biyografik bir roman denemesidir. Burada eserin 'deneme' olarak nitelenmesinin sebebi, bu türün Batı Edebiyatlarında kullanımının sık olmasına karşın Türk Edebiyatında ender olmasından kaynaklanmaktadır. Konu olarak, daha önce ele alınan Eating People is Wrong romanında olduğu gibi, eser üniversitede akademisyenlik yapmış bir profesörün hayatından kesitler sunduğu için bu çalışmada akademik/kampüs roman kategorisinde değerlendirilmektedir. Ancak, her ne kadar Oğuz Atay'ın romanının 
başlı̆̆ında eserin türü 'roman' olarak nitelense de okur bu eserden kurgusal romandan ziyade bir biyografi tadı almaktadır. Çünkü Oğuz Atay eserde anlatı tarzını, olay akışını ve karakter seçimini kronolojik biyografi formunda tercih etmiştir. Ne var ki, yazarının bu eseri roman olarak nitelemesinin ve eserin biyografik roman olarak kabul edilmesinin en büyük destekçisi, eser içinde Mustafa İnan'ın hayatını kitaplaştırma çabası içinde olan ismi belirtilmeyen anlatıcı bir profesör ile yine isminden bahsedilmeyen Adanalı genç bir öğrencinin varlığıdır. Alemdar Yalçın, Bir Bilim Adamının Romanı'nın konusunu şu şekilde özetler:

“Mustafa İnan 1967 yılında öldüğünde, TÜBİTAK Bilim Hizmet Ödülü’nü alacaktır. Adına 1971 yılında bir tören düzenlenir ve üniversiteye gezmeye gelen Adanalı bir genç, kendisini tesadüfen bir tören salonunda bulur. Törenin hazırlanmasından sorumlu bir öğretim üyesi ona, kendisi gibi Adanalı seyyar bir posta dağıtıcısı olan Mustafa İnan'ın hayatını anlatmaya başlar. Cumhuriyetin ilk yıllarında başarılı öğrencilerin devlet bursuyla yurt dışına gönderilmesi ve onların burada yaptıkları çalışmaları anlatan bir romandır. Yazar, hocasının uluslararası başarıları, özel hayatı, sanat, edebiyat ve ülkesine bağglılı̆̆ gibi konuları ele alarak anlatır” (2011: 529).

Burada verilen özet aynı zamanda yukarıda kuramsal olarak tartışılan, genelde Batı Edebiyatlarında akademik/kampüs romanı olarak tanıtılan türle, özelde de Eating People is Wrong romanıla, Bir Bilim Adamının Romanı adlı eserin ne kadar da örtüştüğünün bir göstergesidir. Her iki roman da, içinde bulundukları akademik ortamlara karşı hiciv derecesine varan bir eleştirel yaklaşım göstermektedir. Yukarıda Eating People is Wrong romanında Profesör Treece'in şikâyette bulunduğu öğrencilerin eğitime karşı ilgisizlik ve duyarsızlık halinin bir benzerini Bir Bilim Adamının Romanı'nda Profesör Mustafa İnan şöyle ifade etmektedir:

“Mustafa İnan'ın hocaları da efendi insanlardı, öğrencilerde saygı uyandırıyorlardı. Hepsi de Mustafa'yı seviyorlardı, hepsi de iyi niyetliydi: hocalar da öğrenciler de. Fakat hepsi bu kadardı ve iyi niyetlerle iyi eserler verilemiyordu. Tercüme birkaç kitapla ve derste anlama telaşı içinde tutulan notlarla ve her yil tekrarlanan 'beylik' konularla ve her yıl tekrarlanan basmakalıp örneklerle mühendislik gibi ağır bir öğrenimi yürütmek çok zordu. Derslerde hocaların anlattıkları fikralar bile yıllardır değişmiyordu: öğrenciler Bağdat demiryolunun hikâyelerini dinlemekten yorulmuşlardı. Zaten bu fikraları bir yıl önce tutulan notlarla birlikte eski öğrencilerden temin etmek mümkündü. Bazı hocalar da herhalde kendilerini, daha doğrusu Mustafa İnan'ın deyimiyle 'ithal malı bilimlerini' tekrarlamaktan usanmışlardı, isteksiz görünüyorlardı. Konular gibi, imtihanda sorulan sorular da beylik olduğu için ve Mustafa Bey de kendilerine yardım ettiği için, öğrenciler fire vermeden üst sınıflara geçiyorlardı" (Atay, 1998: 87).

Buradaki alıntıda, Bradbury'nin romanında olduğu gibi eğitim kalitesi düşük olmakla birlikte mühendislik fakültesinde öğrenim gören üniversite öğrencilerinin yanı sıra onlara ders veren hocaların da akademik yönden kendilerini geliştirmeye kapalı ve eğitim-öğretime karşı da ilgisiz olmaları dikkat çekicidir. Eating People is Wrong'ta öğrenciler okula gitmek yerine kafelerde ve öğrenci partilerinde gününü gün ederlerken, Bir Bilim Adamının Romanı'ndaki mühendis adayı öğrenciler derslerde pek bir şey öğrenmeyip sınavlarını kopyayla geçmektedirler. Diğer taraftan, Bir Bilim Adamının Romanı'nda, Eating People is Wrong'tan farklı bir şekilde akademik personel üçüncü şahıslar üzerinden eleştirilmektedir. Bilindiği gibi Eating People is Wrong'ta akademik eleştiri, hem öğrenciler üzerinden hem de direkt olarak romanın başkişisi Profesör Treece üzerinden yapılmaktaydı. Burada ise, biyografisi üzerinden aktarılan Profesör İnan'ın kendisi değil de diğer başka akademisyenler ve akademik dünya eleştirilmektedir:

"Allah Allah dedim, kendi kendime: bir hoca, bir rektör de güler mi? Yarı tanrılar genellikle asık suratlı olurdu; hele o tanrılar mekanik, matematik gibi çok zor şeyleri de bilirlerse. 'Rektör güler mi, diye düşünüyordum. Dekan bile gülmezdi. Değil kürsü başkanları, doçentler bile gülmezdi.' Eren Omay haklıydı; belki asistanlar, ilk acemilik yıllarında biraz gülümserlerdi. Gülmek, doktorayı verdikten sonra unutulan bir eylemdi. Belki eylemsiz doçentler, kadro buluncaya kadar biraz dişlerini gösteriyorlardı (gülümsemek için)" (Atay, 1998: 171).

Yukarıdaki alıntıda dikkat çeken en önemli nokta, ülkemizdeki dönemin üniversitelerindeki akademik yapılanmanın da Eating People is Wrong'taki gibi seçkinci olmasıdır. Daha önce belirtildiği üzere, Eating People is Wrong'ta Profesör Treece gibi alt-iş̧̧i sınıf kökenli akademisyenler kendilerinden önce akademiyi ele geçirmiş üst sınıftan gelme kişilerle mücadele etmek durumundaydılar. Benzer şekilde, Bir Bilim Adamının Romanı'nda Profesör İnan da emekçi bir ailenin çocuğudur ve yukarıdaki alıntıda eleştirdiği akademik seçkinci sınıfla mücadele etmiş ve gayretleri sonucu, üniversitede en yüksek konum olan rektör makamına yükselmiştir. Böylece çalışmanın bu bölümünde Türk Edebiyatından Oğuz Atay'ın üniversiteden hocası Profesör Mustafa İnan için yazdığı Bir Bilim Adamının Romanı akademik/kampüs roman özellikleri bağlamında kısaca değerlendirilmiş oldu. Bundan sonra, sonuç bölümünde, çalışmada konu edinilen Eating People is Wrong ve Bir Bilim Adamının Romanı 
eserlerinin akademik/kampüs roman özellikleri karşılaştırmalı olarak değerlendirilecek ve tespit edilen unsurlar yorumlanacaktır.

\section{SONUÇ}

Daha önce giriş bölümünde belirtildiği üzere, akademik/kampüs roman Batı menşeli ve özellikle İngiliz Edebiyatına mal olmuş bir edebi türdür. Alıntılanan birçok kaynakta da görüldüğü üzere, Malcolm Bradbury'nin Eating People is Wrong romanı şüphesiz bu türün başarılı bir örneği ve akla gelen ilk eserleri arasında yer almaktadır. Bu sebeple, bu çalışmada Eating People is Wrong romanı akademik/kampüs roman normlarının temsilcisi ve yapılan mukayeseli çalışmanın ölçütü olarak kabul edilmektedir. Öyle ki, akademik/kampüs roman türü Türk Edebiyatında çok bilinen ve örneği fazla olan bir tür değildir. Üstelik daha önce de belirtildiği üzere, Bir Bilim Adamının Romanı edebi tür olarak biyografik roman türüne girmektedir. O yüzden bu çalışmada Bir Bilim Adamının Romanı'nın tasarlandığı ve genel olarak kabul edildiği edebi türden farklı bir kategoride değerlendirilmesi, edebiyat çalışmaları açısından da şüphesiz özel bir öneme sahiptir. Belirtildiği üzere, akademik/kampüs roman türü daha çok Batılı eserlerde görülse de ve yine belirtildiği üzere, Bir Bilim Adamının Romanı aslen biyografik roman türünde kaleme alınmış olsa da, aynı zamanda pek çok akademik/kampüs roman özelliğini de bünyesinde barındırmaktadır. Örneğin romanın başkahramanı, Eating People is Wrong'ta olduğu gibi, bir profesördür. Benzer şekilde, roman mekân olarak bir üniversitede geçmektedir. Ve yine, Profesör Mustafa İnan, tıpkı Eating People is Wrong'taki Profesör Treece gibi devletin eğitim haklarından faydalanarak eğitim almış ve daha sonra üniversiteye hoca olarak geri dönmüştür. Bütün bu akademik/kampüs romanı özelliklerinin yanı sıra, yine Profesör Treece gibi, Profesör İnan da emekçi ve fakir sınıf bir aileden gelmektedir.

Yukarıda belirtilen akademik/kampüs romanı özellikleri bağlamında, Eating People is Wrong ve Bir Bilim Adamının Romanı eserlerinin benzerlikleri yanı sıra her iki eser arasında bazı farklılıklar da göze çarpmaktadır. Örneğin, Eating People is Wrong'da, dönem ve toplum eleştirisi daha çok romanın başkişisi özelinde öznel eleştiri şeklinde ilerlerken, Bir Bilim Adamının Romanı'nda akademik dünya eleştirisi üçüncü şahıslar üzerinden yapılmaktadır. Bunun en büyük sebebi, Eating People is Wrong'un baştan itibaren, romanın başkahramanını ve onun iş çevresini eleştirmek maksadıyla kaleme alınan bir eser olmasıdır. Başka bir ifadeyle, Eating People is Wrong romanında öncelik, akademik başkişi ve üniversite ortamı eleştirisi üzerinedir. Diğer taraftan, Bir Bilim Adamının Romanı ise baştan sona biyografik roman türünde kurgulandığı için amaç direkt olarak akademik kişi ve ortamları eleştirmek değil, başarılı bir profesörün yaşam hikâyesini kurgusal olarak aktarmaktır. Bu sebeple biyografik eserlerin genel formatına bağlı kalınarak Bir Bilim Adamının Romanı'nda Profesör İnan'ın olumlu ve başarılı yönleri öncelenirken, İnan'ın hayatındaki olumsuzluklar ve eleştiriler üçüncü şahıslar üzerinden ifade edilmektedir.

Son olarak her iki eser için, akademik/kampüs roman özelliklerine bağlı olarak, şu tespitleri yapmak mümkündür: hem Eating People is Wrong hem de Bir Bilim Adamının Romanı'nda, eserlerin yazıldığ dönem ve toplum özelliklerine bağlı olarak, akademisyenler mesleklerine ve verdikleri derslere karşı isteksiz ve öğrenciler de eğitimlerine karşı ilgisiz bir şekilde resmedilmişlerdir. Her iki eserdeki akademik dünyaya karşı sergilenen bu eleştirel tutum, her iki eserin konuları ele alış ve onları ifade etme biçimindeki farklılıklarına rağmen, iki eserin de akademik/kampüs roman türüne örnek teşkil edecek derecede özgün özelliklere sahip olduklarının en büyük göstergesidir. 


\section{KAYNAKLAR}

Abrams, M. H. (1999). A Glossary of Literary Terms, Harcourt, Brace College Publishers.

Atay, O. (1998). Bir Bilim Adamının Romanı, İletişim yayınları.

Baldick, C. (2001). The Concise Oxford Dictionary of Literary Terms, Oxford University Press.

Bradbury, M. (1962). Eating People is Wrong, Penguin.

Bradbury, M. (1994). The Modern British Novel, Penguin.

Bradbury, M. (2021). Fiction_Eating_People_is_Wrong. [Erişim: 26.09.2021, http://malcolmbradbury.com/fiction_eating_people_is_wrong.html]

Connor, S. (2001). The English Novel in History: 1950-1995, Routledge.

Hawthorn, J. (2001). Studying the Novel: An Introduction, Arnold.

Head, D. (2002). The Cambridge Introduction to Modern British Fiction, 1950-2000, Cambridge Univ. Press.

Lodge, D. (2000). Introduction. Lucky Jim. Kingsley Amis, Penguin.

Sanders, A. (1994). The Short Oxford History of English Literature, Oxford University Press.

Shaffer, B. W. (2006). Reading the Novel in English, 1950-2000, Blackwell Pub.

Ören, A. (2014). Kampüs Roman ve Davıd Lodge'un Kampüs Romanları. Uluslararası Hakemli Iletişim ve Edebiyat Araşttrmaları Dergisi, 2 (4), 85-96.

Womack, K. (2002). Postwar Academic Fiction: Satire, Ethics, Community, Palgrave.

Yalcın, A. (2011). Cumhuriyet Dönemi Çağdaş Türk Romanı 1946-2000, Akçağ. 